\title{
COMPETITIVIDADE NODULAR DE ESTIRPES DE BRADYRHIZOBIUM SPP. EM CULTIVARES DE SOJA SOB DIFERENTES DISPONIBILIDADES HÍDRICAS
}

\author{
Esmael Lopes dos Santos ${ }^{1 *}$, Alexandre Lima Nepomuceno ${ }^{2}$, Cassio Egidio Cavenaghi Prete ${ }^{1}$, \\ Norman Neumaier ${ }^{2}$, Maria Cristina Neves de Oliveira ${ }^{2}$, José Renato Bouças Farias ${ }^{2}$, \\ Alexandre José Cattelan ${ }^{2}$
}

RESUMO: O objetivo do trabalho foi avaliar a competitividade nodular de estirpes de Bradyrhizobium spp. em cultivares de soja sob diferentes disponibilidades hídricas a campo. Foi realizada análise conjunta dos dados de duas safras (2006/07 e 2007/08), com dez cultivares de soja (BR 16, Embrapa 48, BRS 133, BRS 134, BRS 245 RR, BRS 247 RR, BRS 183, BRS 184, BRS 214, e BRS 232), que foram submetidas a três disponibilidades hídricas (1 - DHER, déficit hídrico nos estádios reprodutivos; 2 - CNC, condições normais de campo e 3 - IRR, irrigado) em delineamento experimental de blocos ao acaso, em parcelas subdivididas, com quatro repetições. Os nódulos foram tipificados pelo método de ELISA, com antissoros das estirpes SEMIA 5079, SEMIA 5080, SEMIA 587 e SEMIA 5019. As estirpes inoculadas (SEMIA 587 e SEMIA 5019) foram mais competitivas para nodulação em relação às estirpes naturalizadas no solo. A estirpe SEMIA 587 foi a de maior ocupação nodular, inclusive quando houve limitação hídrica nos estádios reprodutivos. A SEMIA 5080 (não inoculada) foi a que apresentou a menor ocupação nodular entre as estirpes analisadas.

Palavras-chave: FBN, estresse hídrico, rizóbio e seca.

\section{COMPETITIVENESS OF DUCTILE Bradyrhizobium SPP. IN VARIETY OF DIFFERENT SOYBEAN UNDER WATER AVAILABILITY}

\begin{abstract}
The aim of this work was to evaluate the competitive nodulation of Bradyrhizobium spp. strains in soybean cultivars under different water availability. It was perfomed a joint analysis of pooled data from two crop seasons (2006/07 and 2007/08) with variations in rain precipitation. Ten soybean cultivars (BR 16, Embrapa 48, BRS 133, BRS 134, BRS 245 RR, BRS 247 RR, BRS 183, BRS 184, BRS 214 and BRS 232), were submitted to three water availability conditions (1 - DHER, water stress during the reproductive stages; 2 - CNC, field condition and 3 - IRR, irrigated) in a randomized complete block design in split plots with four replications. The nodules were classified by ELISA with antiserum of SEMIA 5079, SEMIA 5080, SEMIA 587 and SEMIA 5019. The inoculated strains (SEMIA 587 and SEMIA 5019) were more competitive for nodulation against the naturalized strains in soil. The SEMIA 587 have the highest nodule occupation, even when there was water stress conditions in reproductive stages. The SEMIA 5080 (not inoculated) was the one with the smallest nodule occupation among the strains analyzed.
\end{abstract}

Keywords: FBN, water stress and rhizobia and drought.

\footnotetext{
${ }^{1}$ Empresa Brasileira de Pesquisa Agropecuária - Centro Nacional de Pesq. Soja, Manejo do Solo e da Cultura. Rod. Carlos João Strass s/n Warta. CEP: 86001-970, Londrina, PR - Brasil. E-mail: esmael@ cnpso.embrapa.br. *Autor para correspondência.

${ }^{2}$ Departamento de Agronomia, Universidade Estadual de Londrina, Rod. Celso Garcia Cid, Pr 445, Km 380. CEP: 86051-990, Londrina, PR-Brasil.

Recebido em: 31/07/2013

Aprovado em: 03/12/2013
} 


\section{INTRODUÇÃO}

O uso de inoculante com bactérias fixadoras de nitrogênio do gênero Bradyrhizobium spp. é, atualmente, uma tecnologia indispensável para a cultura da soja no Brasil (ZILLI et al., 2010). A fixação biológica do nitrogênio FBN representa um dos principais fatores de competitividade da cultura da soja (ZILLI et al., 2008).

No entanto, a FBN é sensível ao estresse hídrico, dependendo da época e da intensidade que ocorre (SANTOS et al., 2012). A limitação hídrica pode comprometer a sobrevivência de Bradyrhizobium spp., bactéria que ao entrar em contato com as raízes da soja, infecta as raízes, via pelos radiculares, formando os nódulos onde ocorre a FBN. Pode ainda limitar a formação e longevidade dos nódulos e a síntese leghemoglobina responsável pelo transporte de $\mathrm{O}_{2}$. Além disso, o estresse mais severo pode levar à paralisação da fixação (FAGAN et al., 2007), e por consequência comprometer o rendimento e a composição química dos grãos (SANTOS et al., 2012).

Conforme Kron et al., (2008), a sensibilidade da soja às deficiências hídricas, considerando o rendimento de grãos, tende a aumentar à medida que a cultura avança no seu ciclo, apresentando máxima sensibilidade durante o período reprodutivo, principalmente na formação de legumes e enchimento de grãos. Neste período, por consequência, há também maior demanda por $\mathrm{N}_{2}$ (nitrogênio) pela planta (STREETER, 2003).

No entanto, variações genéticas em espécies leguminosas quanto à capacidade para fixar $\mathrm{N}_{2}$ sob estresse hídrico tem sido evidenciada por alguns autores (ASHRAF \& IRAM, 2005; CHARLSON et al., 2009), e a variação nos níveis de umidade nos ecossistemas, onde leguminosas foram submetidas para fixar nitrogênio, sugere variabilidade genética entre as estirpes quanto á sensibilidade ao estresse hídrico (MNASRI et al., 2007).

Desta forma, a avaliação da capacidade de ocupação dos nódulos pode fornecer subsídios em relação à capacidade de sobrevivência, estabelecimento e competitividade da estirpe inoculada em relação a outros rizóbios presentes no solo ou com estirpes já introduzidas (MARTINS et al., 2003), sob condições de déficit hídrico. Portanto, o objetivo do trabalho foi avaliar a competitividade nodular de estirpes de Bradyrhizobium spp. em cultivares de soja sob diferentes disponibilidades hídricas a campo.

\section{MATERIAL E MÉTODOS}

Os experimentos foram conduzidos nas safras 2006/07 e 2007/08, no campo experimental da Embrapa Soja, em Londrina-PR, (latitude $23^{\circ} 11 \mathrm{~S}$, longitude $51^{\circ} 11 \mathrm{~W}$ e altitude $566 \mathrm{~m}$ ). Seguindo a metodologia utilizada por Santos et al., (2012), as semeaduras dos experimentos foram realizadas manualmente com o revolvimento do solo somente nas linhas, com espaçamento de $0,45 \mathrm{~cm}$, deixando após o desbaste 12 plantas/m. A inoculação das sementes de soja foi realizada conforme Hungria et al., (2007), com inoculante turfoso, contendo as estirpes SEMIA $587+$ SEMIA 5019 com concentração mínima de $5 \times 10^{9}$ células viáveis/grama, numa dosagem de $200 \mathrm{~g} / 50$ $\mathrm{kg}$ de sementes, e o tratamento das sementes com o fungicida VitavaxThiram $^{\circledR}$, na dosagem de $250 \mathrm{~g} / 100 \mathrm{~kg}$ de sementes. O controle de pragas e doenças foi realizado de acordo com as recomendações das Tecnologias de Produção de Soja para a Região Central do Brasil 2006 (EMBRAPA, 2005).

$\mathrm{O}$ delineamento experimental utilizado foi o de blocos ao acaso em parcelas subdivididas, com quatro repetições. Nas parcelas, três disponibilidades hídricas $(1$ - DHER, déficit hídrico nos estádios reprodutivos; 2 
- CNC, condições normais de campo e 3 IRR, irrigado) e em subparcelas, as 10 cultivares de soja, comuns, nas duas safras (BR 16, Embrapa 48, BRS 133, BRS 134, BRS 245 RR, BRS 247 RR, BRS 183, BRS 184, BRS 214 e BRS 232). As cultivares foram mantidas em condições de campo até o estádio $\mathrm{R}_{1}$, mas após este estádio no tratamento disponibilidade hídrica DHER, foram utilizados abrigos móveis, com fechamento automático, para evitar a precipitação pluviométrica sobre as parcelas.

Os dados meteorológicos observados no período das safras 2006/07 e 2007/08 estão expressos nas Figuras 1 e 2 , respectivamente.

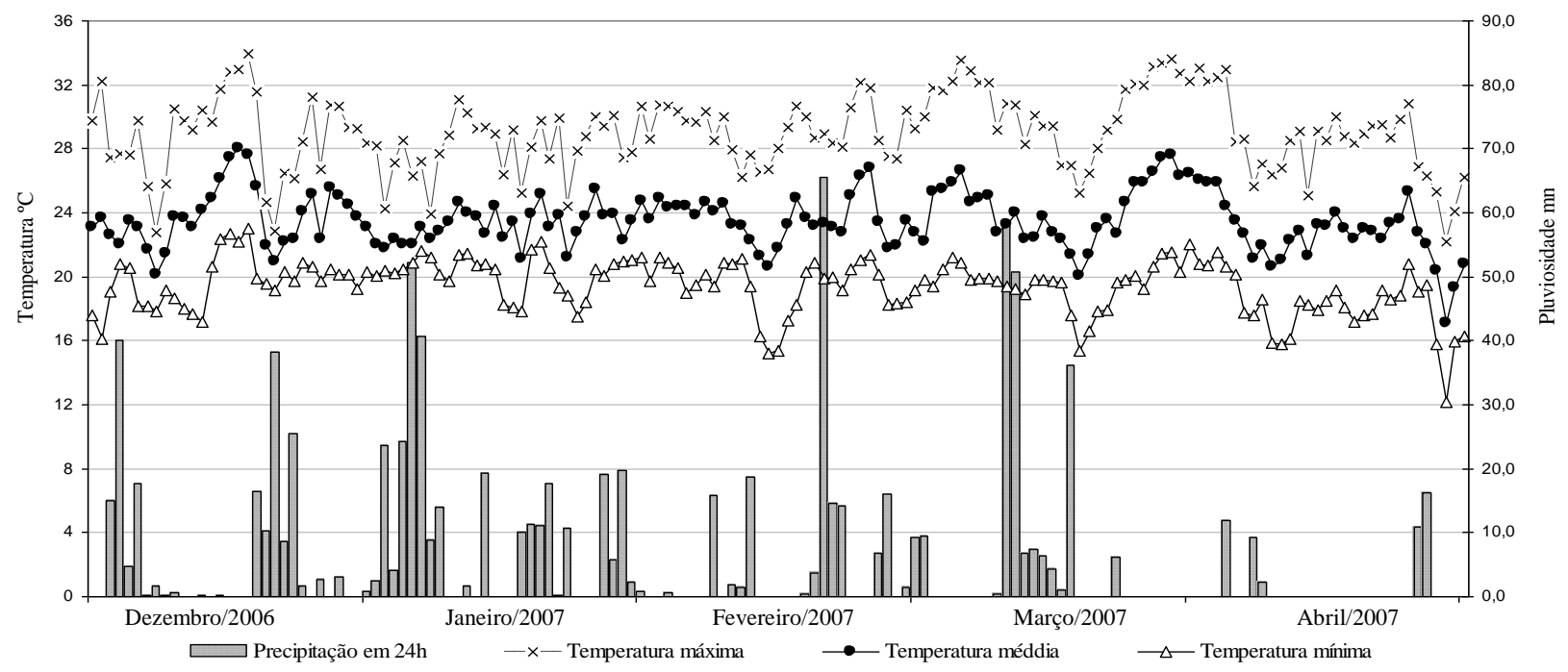

Figura 1. Pluviosidade acumulada diariamente, temperaturas máxima, mínima e média diárias, observadas no período de condução do experimento na safra 2006/07.

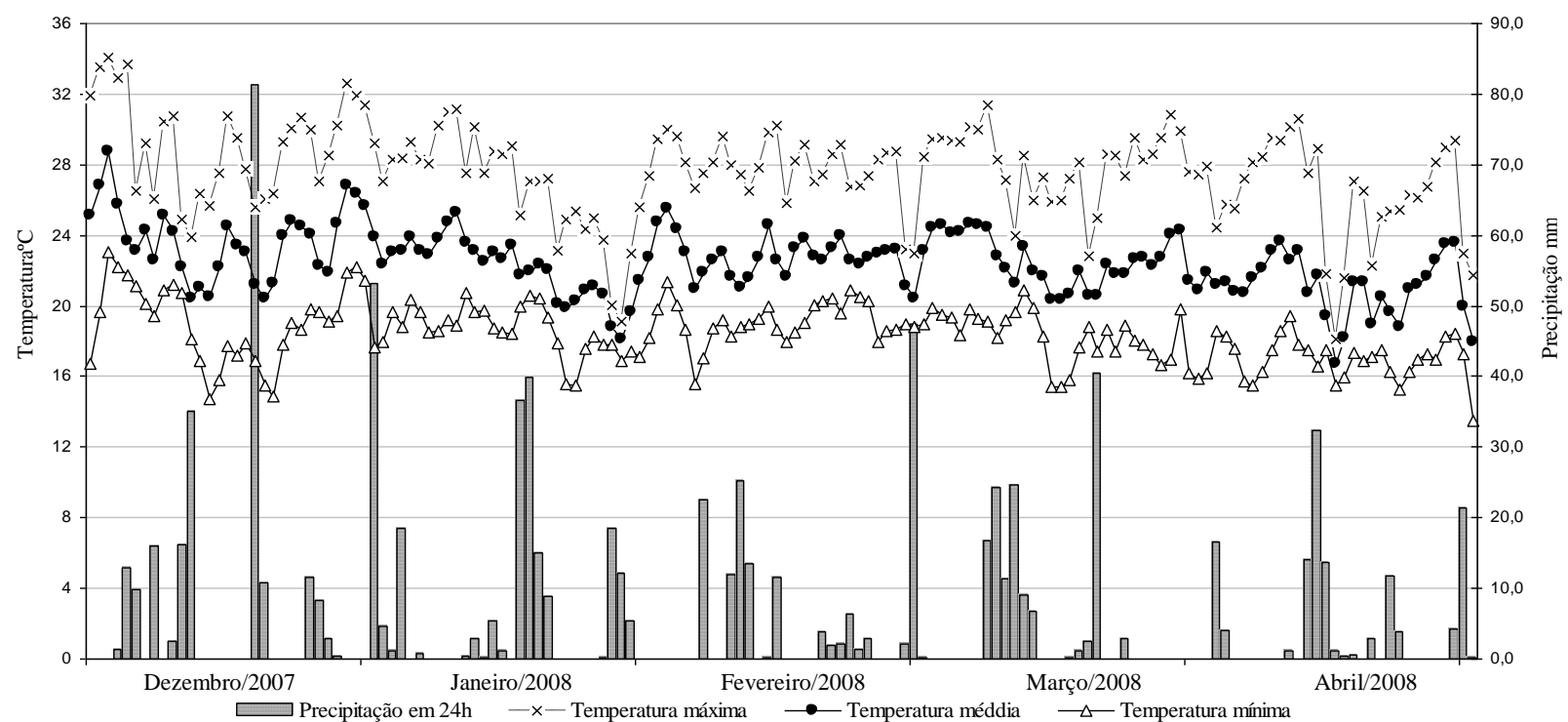

Figura 2. Pluviosidade acumulada diariamente, temperaturas máxima, mínima e média diárias, observadas no período de condução do experimento na safra 2007/08.

No estádio $\mathrm{R}_{8}$, foram coletadas cinco plantas de cada subparcela, logo após procedeu-se a separação dos nódulos das raízes e, em seguida, os mesmos foram lavados em água corrente e secos em estufa $\left(65^{\circ} \mathrm{C}\right)$, com aeração forçada. 
Posteriormente, retirou-se dez nódulos, ao acaso, de cada uma das subparcela, para serem analisados por meio da reação de imunoadsorção com enzima acoplada (Elisa). Para esta reação, inicialmente, foram produzidos os antissoros com as quatro estirpes de Bradyrhizobium spp. utilizadas, conforme metodologia proposta por Fuhrmann e Wollum (1985).

Os métodos estatísticos utilizados constituíram-se de um diagnóstico exploratório, seguido da análise de variância (ANOVA). Além da análise de variância, aplicou-se também o teste de comparações múltiplas de médias de Tukey ao nível de significância de 0,05 . Os dados, quando necessário, foram transformados para $\mathrm{y}=\sqrt{x+0,5}$, sendo apresentados nas tabelas os dados originais.

\section{RESULTADOS E DISCUSSÃO}

Tabela 1. Resumo da análise de variância, da ocupação nodular das estirpes de Bradyrhizobium spp., e para a os nódulos que obtiveram reação com mais de uma estirpe (reação cruzada) e sem reação com os sorotipos utilizados. Londrina - PR, 2013

\begin{tabular}{|c|c|c|c|c|c|c|c|}
\hline \multirow{2}{*}{ Fonte de Variação } & \multirow{2}{*}{ G.L. } & \multicolumn{6}{|c|}{ Quadrados médios } \\
\hline & & SEMIA 587 & SEMIA 5019 & SEMIA 5079 & SEMIA 5080 & Reação Cruzada & Sem reação \\
\hline Bloco & 3 & $0.001 \mathrm{~ns}$ & $0,074 \mathrm{~ns}$ & $0,618 \mathrm{~ns}$ & $0.077 \mathrm{~ns}$ & $0,014 \mathrm{~ns}$ & $0,001 \mathrm{~ns}$ \\
\hline Disponibilidade Hídrica (DH) & 2 & $4.456^{*}$ & $0.695 \mathrm{~ns}$ & $1.100 \mathrm{~ns}$ & $0.923^{*}$ & $0.990 \mathrm{~ns}$ & $3.733^{*}$ \\
\hline Resíduo (a) & 6 & & & & & & \\
\hline Parcelas & 11 & & & & & & \\
\hline Cultivar (Cult) & 9 & $1.025 \mathrm{~ns}$ & $1.063 \mathrm{~ns}$ & $0.821 \mathrm{~ns}$ & $0.117 \mathrm{~ns}$ & $0.201 \mathrm{~ns}$ & $0.709 \mathrm{~ns}$ \\
\hline DH X Cult & 18 & $0.494 \mathrm{~ns}$ & $0.238 \mathrm{~ns}$ & $0.358 \mathrm{~ns}$ & $0.099 \mathrm{~ns}$ & $0.282 \mathrm{~ns}$ & $0.387 \mathrm{~ns}$ \\
\hline Resíduo (b) & 81 & & & & & & \\
\hline Subparcelas & 119 & & & & & & \\
\hline Safra & 1 & $4.248 *$ & $4.529 *$ & $0.050 \mathrm{~ns}$ & $0.101 \mathrm{~ns}$ & $4.585^{*}$ & $6.282^{*}$ \\
\hline DH X Safra & 2 & $0.752 \mathrm{~ns}$ & $0.260 \mathrm{~ns}$ & $1.728 \mathrm{~ns}$ & $0.080 \mathrm{~ns}$ & $0.158 \mathrm{~ns}$ & $0.877 \mathrm{~ns}$ \\
\hline Cult X Safra & 9 & $0.727 \mathrm{~ns}$ & $0.577 \mathrm{~ns}$ & $1.027 \mathrm{~ns}$ & $0.131 \mathrm{~ns}$ & $0.567 \mathrm{~ns}$ & $0.319 \mathrm{~ns}$ \\
\hline DH X Cult X Safra & 18 & $0.296 \mathrm{~ns}$ & $0.435 \mathrm{~ns}$ & $0.316 \mathrm{~ns}$ & $0.118 \mathrm{~ns}$ & $0.435 \mathrm{~ns}$ & $0.152 \mathrm{~ns}$ \\
\hline Resíduo (c) & 90 & & & & & & \\
\hline Total & 239 & & & & & & \\
\hline C.V.\% & & 29,41 & 24,46 & 33,46 & 34,64 & 41,32 & 18,54 \\
\hline
\end{tabular}


Entre as estirpes, houve respostas diferentes quando houve variação na disponibilidade hídrica (Figura 3), sendo a SEMIA 587 e SEMIA 5019 as estirpes que apresentaram maiores porcentagens de ocupação nodular na disponibilidade hídrica IRR (Irrigado), com diferença significativa em relação às outras disponibilidades, mostrando maior eficiência competitiva com outras estirpes presentes no solo quando houve uma melhor distribuição hídrica. Maehler et al., (2003) argumentam que sistemas de manejo do solo, resultam em maior infiltração e conservação da água e diminuição da temperatura no solo e, também, o uso adequado da irrigação pode constituir-se em práticas complementares para melhores condições de nodulação e da FBN.

As maiores porcentagens de nódulos apresentaram reação sorológica com as estirpes inoculadas, SEMIA 587 e SEMIA 5019, mostrando-se mais competitivas. Hungria et al., (2006), também sugerem que estas estirpes são mais competitivas. Entre as duas estirpes, a SEMIA 587 mostrou ser mais competitiva, pois apresentou maiores porcentagens de ocupação nodular em todas as disponibilidades hídricas. Estes resultados demonstram a importância da reinoculação (ARAÚJO \& HUNGRIA, 1999; HUNGRIA et al., 2007), que pode proporcionar ganhos no rendimento de grãos da soja, reforçando a recomendação dessa prática, que deve ser efetuada a cada cultivo.

Quando não houve reação sorológica (sem reação) com as estirpes estudadas, a diferença estatística foi com as maiores porcentagem nos ambientes, onde houve disponibilidade hídrica CNC e IRR, e, mesmo não tendo sido inoculadas, ainda assim, as estirpes SEMIA 5079 e SEMIA 5080 apresentaram reação sorológica positiva, porém com valores relativamente baixos. No entanto, observa-se uma nodulação natural abundante em decorrência da sobrevivência das estirpes de inoculações anteriores, sendo que a inoculação com as estirpes atualmente recomendadas contribuíram para o aumento na ocupação dos nódulos por essas estirpes (WATKIN et al., 2000). Resultados semelhantes foram obtidos por Lima et al., (1998) quando caracterizaram rizóbios (Bradyrhizobium japonicum) e produtividade da soja.

$\mathrm{Na}$ análise de ocupação dos nódulos, a soma das percentagens de nódulos ocupados por cada sorogrupo foi superior a $100 \%$, pois alguns nódulos reagiram com mais de um antissoro (reação cruzada), sugerindo a presença de diferentes estirpes no mesmo nódulo. Hungria et al., (2006), com trabalhos realizados em Londrina constataram que $10,2 \%$ dos nódulos foram ocupados por estirpes com mais de um sorogrupos, no entanto, no presente trabalho os valores foram abaixo de $5 \%$ e não houve diferença estatística entre as disponibilidades hídricas. 


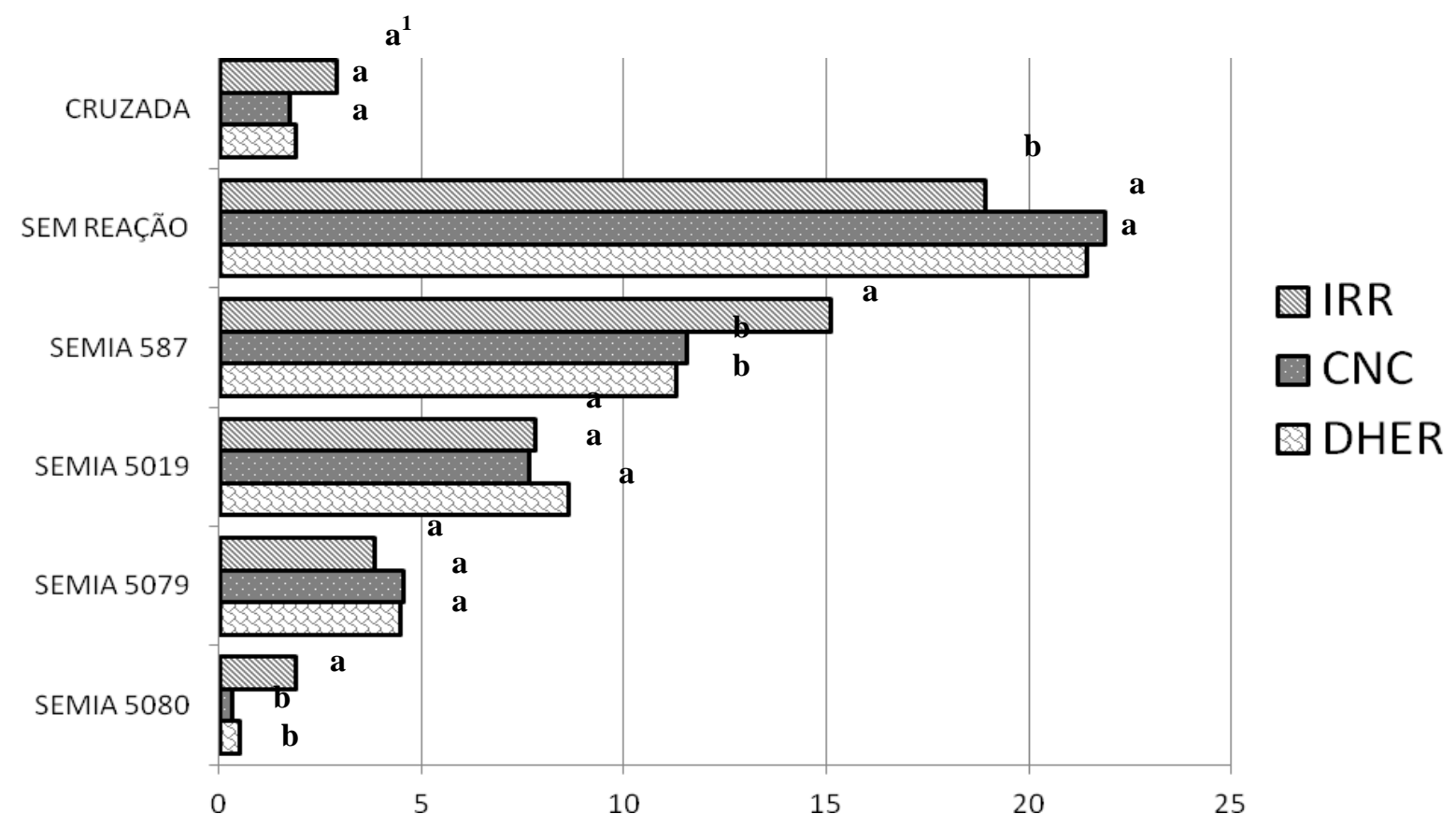

Porcentagem de nódulos

Figura 3. Ocupação nodular de Bradyrhizobium spp. das estirpes SEMIA 5079, SEMIA 5080, SEMIA 5019 e SEMIA 587 em três disponibilidades hídricas (IRR, Irrigado; CNC, Condições normais de campo e DHER, Déficit hídrico nos estádio reprodutivos) em dez cultivares de soja, em duas safras (2006/07 e 2007/08). Londrina - PR. ${ }^{1}=$ Médias seguidas de mesma letra, comparada em cada estipe, não diferem entre si a 5\% de probabilidade pelo teste de Tukey.

Já em relação às médias de ocupação nodular (Tabela 2), mostra que houve diferenças estatísticas entre as duas safras estudadas e as quatro estirpes estudadas apresentaram as maiores médias na safra 2006/07, no entanto, os dados de pluviosidade acumulada, temperaturas diárias em máxima, mínima e média (Figura 1 e 2) observadas no período da condução dos experimentos apresentaramse próximos. Variação na ocupação nodular entre safras distintas, também foi encontrado por Campos et al. (2001), quando avaliaram a capacidade competitiva e a eficiência na fixação do $\mathrm{N}_{2}$ das combinações das quatro estirpes de Bradyrhizobium spp. recomendadas comercialmente (SEMIA 587, SEMIA 5019, SEMIA 5079 e SEMIA 5080) para a cultura da soja em duas safras.

Nas duas safras as estirpes SEMIA 587 e SEMIA 5019 apresentaram melhor habilidade competitiva, mostrada pela maior ocorrência de nódulos. O fato de estas estirpes apresentarem maiores porcentagens de ocupação nodular se deve também a melhor capacidade de competir por sítios de nodulação no campo pela espécie Bradyrhizobium elkanii, e pela sua maior adaptabilidade às condições adversas dos solos tropicais (ZILLI et al, 2006), como é o caso da variação na disponibilidade hídrica, além de serem utilizadas na inoculação das sementes. 
Tabela 2. Médias da ocupação nodular de estirpes de Bradyrhizobium spp. na análise conjunta de duas safras (2006/07 e 2007/08), em três disponibilidades hídricas (IRR, Irrigado; CNC, Condições normais de campo e DHER, Déficit hídrico nos estádio reprodutivos) com dez cultivares de soja. Londrina - PR

Safras SEMIA 587 SEMIA 5019 SEMIA 5079 SEMIA 5080 Reação cruzada Sem reação

\begin{tabular}{llllllllll}
\hline $2006 / 07$ & 15,43 & $\mathrm{~A}^{1}$ & 8,79 & $\mathrm{~A}$ & 4,31 & $\mathrm{~A}$ & $0,45 \mathrm{~A}$ & $2,74 \mathrm{~A}$ & $17,75 \mathrm{~B}$ \\
$2007 / 08$ & 9,92 & $\mathrm{~B}$ & $7,30 \mathrm{~B}$ & $4,30 \mathrm{~A}$ & $0,24 \mathrm{~A}$ & $1,63 \mathrm{~B}$ & $23,57 \mathrm{~A}$ \\
\hline CV\% $=$ & 29,41 & 24,46 & 33,46 & 34,64 & 41,32 & 18,54 \\
\hline
\end{tabular}

\section{CONCLUSÕES}

Quando há disponibilidade hídrica, as estirpes inoculadas (SEMIA 587 e SEMIA 5019) são mais competitivas para nodulação em relação às estirpes naturalizadas no solo.

Mesmo com limitação hídrica a estirpe SEMIA 587 foi a de maior ocupação nodular, mostrando ser a mais indicada nestas condições.

A SEMIA 5080 (não inoculada) foi a que apresentou a menor ocupação nodular entre as estirpes analisadas, demonstrando que as estirpes naturalizadas apresentam baixa competitividade para a nodulação.

\section{REFERÊNCIAS}

ARAUJO, F. F.; HUNGRIA, M. Nodulação e rendimento de soja coinfectada com Bacillus Subtilis e Bradyrhizobium Japonicum / Bradyrhizobium Elkanii. Pesquisa Agropecuária Brasileira. Brasília, v. 34, n. 9, 1999.

ASHRAF M., IRAM A.T. Drought stress induced changes in some organic substances in nodules and other plant parts of two potential legumes differing in salt tolerance. Flora. v. 200, p.535-546, 2005.

CAMPOS, B.C.; HUNGRIA, M. \& TEDESCO, V. Eficiência da fixação biológica de $\mathrm{N}_{2}$ por estirpes de Bradyrhizobium na soja em plantio direto.
Revista Brasileira de Ciências do solo, v. 25, pp. 583-592, 2001.

CHARLSON, D.V., KORTH, K.L., PURCELL, L.C. Allantoate amidohydrolase transcript expression is independent of drought tolerance in soybean. Jounal of Experimental Botany, London, v.60, n.3, p.84-851, 2009.

EMBRAPA. Centro Nacional de Pesquisa de Soja. Tecnologia de produção de soja: região central do Brasil - 2006. Londrina: Embrapa Soja, 2005. 220p. (Sistema de produção, 9).

FAGAN, E. B.; MEDEIROS, S. L. P.; MANFRON, P. A.; CASAROLIL, D.; SIMON, J.; DOURADO NETO, D.; LIER, Q. J. van; SANTOS, O. S.; MÜLLER, L. Fisiologia da fixação biológica do nitrogênio em soja. Revista da Faculdade de Zootecnia, Veterinária e Agronomia, Uruguaiana, v.14, f.1, p.89-106, 2007.

FUHRMANN, J.; WOLLUM II, G. Simplified enzyme-linked immunosorbent assay for routine identification of Rhizobium japonicum antigens. Appl. Environ. Microbiol., v. 49, n. 4, p. 10101013, 1985.

HUNGRIA, M.; CAMPO, R.J.; MENDES, I. C.; A importância do processo de fixação biológica do nitrogênio para a cultura da soja: componente essencial para as competitividades do produto brasileiro. Londrina: Embrapa Soja, 2007. 80 p. (Embrapa Soja. Documentos, 283). 
HUNGRIA, M.; CHUEIRE, L.M.O.; MEGÍAS, M.; LAMRABET, Y.; PROBANZA, $\quad$ A.; GUTTIERREZMANERO, F.J.; CAMPO, R.J. Genetic diversity of indigenous tropical fast-growing rhizobia isolated from soybean nodules. Plant and Soil, v. 288, p. 343-356, 2006.

KRON, A. P; SOUZA, G. M; RIBEIRO, R. V. Water deficiency at different developmental stages of Glycine max can improve drought tolerance. Bragantia, Campinas, v.67, n.1, p.43-49, 2008.

LIMA, S. C.; LOPES, E. S.; LEMOS, E. G. M. Caracterização de rizóbios (Bradyrhizobium japonicum) e produtividade da soja. Scientia Agricola, Piracicaba, v. 55, p. 360-366, 1998.

MAEHLER, A.R.; PIRES, J.L.F.; COSTA, J.A.; FERREIRA, F.G. Potencial de rendimento da soja durante a ontogenia em razão da irrigação e arranjo de plantas. Pesquisa Agropecuária Brasileira, v.38, p.225-231, 2003.

MARTINS, L. M. V.; XAVIER,G. R.; RANGEL, F. W.; RIBEIRO, J. R. A.; NEVES, M. C. P.; MORGADO, L. B.; RUMJANEK, N. G. Contribution of biological nitrogen fixation to cowpea: a strategy for improving grain yield in the semi -arid region of Brazil. Biology and Fertility of Soil, v. 38, p. 333-339, 2003.

MNASRI, B., MRABET, M., LAGUERRE, G., AOUANI, M. E., \& MHAMDI, R. Salt-tolerant rhizobia isolated from a Tunisian oasis that are highly effective for symbiotic N 2-fixation with Phaseolus vulgaris constitute a novel biovar (bv. mediterranense) of Sinorhizobium meliloti. Archives of Microbiology, v. 187, n. 1, p. 79-85, 2007.

SANTOS, E. L. dos; CATTELAN, A.J.; PRETE, C.E.C.; NEUMAIER, N.; OLIVEIRA, M.C.N. de; FARIAS, J.R.B.; CARVALHO, J.F.C.; NEPOMUCENO, A.L. Water stress affecting nodulation, oil, protein and grain yield of soybean cultivars. Global Science and Tecnology. Rio Verde, v. 5, n. 2, p. 109 - 120, 2012.

SANTOS, M. A. dos; NICOLAS, M. F.; HUNGRIA, M. Identificação de QTL associados à simbiose entre Bradyrhizobium japonicum, B. elkanii e soja. Pesquisa Agropecuária Brasileira, Brasília, v. 41, n. 1, p. 67-75, 2006.

SOUZA, R.A.; HUNGRIA, M.; FRANCHINI, J.C.; MACIEL, C.D.; CAMPO, R.J.; ZAIA, D.A.M. Conjunto mínimo de parâmetros para avaliação da microbiota do solo e da fixação biológica do nitrogênio pela soja. Pesquisa Agropecuária Brasileira, v. 43, p. 83-91, 2008.

STREETER, J. G. Effects of drought on nitrogen fixation in soybean root nodules. Plant, Cell and Environment, V. 26, P. 1199-1204, 2003.

ZILLI, J.E.; MARSON, L.C.; CAMPO, R.J.; GIANLUPPI, V.; HUNGRIA, M.; SMIDERLE, O.J. Avaliação da fixação biológica de nitrogênio na soja em áreas de primeiro cultivo no cerrado de Roraima. Embrapa Roraima, 2006. 9p. (Embrapa Roraima. Comunicado Técnico, 20).

ZILLI, J.E.; MARSON, L.C.; MARSON, B.F.; CAMPO, R.J. \& HUNGRIA, M. Inoculação de Bradyrhizobium em soja por pulverização em cobertura. Pesquisa Agropecuária Brasileira, 43:541-544, 2008.

ZILLI, J. É.; CAMPO, R. J.; HUNGRIA, M. Eficácia da inoculação de Bradyrhizobium em pré-semeadura da soja. Pesquisa Agropecuária Brasileira, v. 45, n.3, p. 335-337, 2010.

WATKIN, E.L.J.; O'HARA, G.W.; HOWIESON, J.G.; GLENN, A.R. Identification of tolerance to soil acidity in inoculant strains of Rhizobium leguminosarum bv. trifolii. Soil Biology \& Biochemistry, v.32, p.1393-1, 2000. 